\title{
Epidemiology of Liver Cancer in Latin America: Current and Future Trends
}

\author{
Flair Jose Carrilho, MD, $\mathrm{PhD}^{1,2}$ Denise Cerqueira Paranaguá-Vezozzo, MD ${ }^{1,2}$ Aline Lopes Chagas, MD ${ }^{1,2}$ \\ Regiane Saraiva de Souza Melo Alencar, MD ${ }^{1,2}$ Leonardo Gomes da Fonseca, MD ${ }^{2}$
}

\author{
1 São Paulo Clínicas Liver Cancer Group - Hospital das Clínicas \\ Complex, Division of Clinical Gastroenterology and Hepatology, \\ Department of Gastroenterology, University of São Paulo School of \\ Medicine, São Paulo, Brazil \\ 2 São Paulo Clínicas Liver Cancer Group - Hospital das Clínicas \\ Complex, Instituto do Cancer do Estado de São Paulo, University of \\ São Paulo School of Medicine, São Paulo, Brazil
}

\begin{abstract}
Address for correspondence Flair Jose Carrilho, MD, PhD, São Paulo Clínicas Liver Cancer Group - Hospital das Clínicas Complex, Division of Clinical Gastroenterology and Hepatology, Department of Gastroenterology, University of São Paulo School of Medicine, Av Dr. Eneás Carvalho de Aguiar, 255 ICHC - 9th floor, Room 9159, São Paulo, SP 05403-000, Brazil (e-mail: fjcarril@usp.br).
\end{abstract}

\begin{abstract}
Keywords

- Latin America

- demographics

- hepatocellular carcinoma

- risk factors

Over 38,000 cases of hepatocellular carcinoma (HCC) are estimated to occur in Latin America annually. The region is characterized by sociocultural heterogeneity and economic disparities, which impose barriers in addressing this major health issue. A significant proportion of patients are still diagnosed in the later stages of the disease, although efforts to implement effective screening programs have been reported by referral centers. While viral hepatitis remains the predominant etiology of liver disease among HCC cases in Latin America, a high prevalence of fatty liver disease in the region is a matter of concern, reflecting the current scenario in many Western countries. In addition, other risk factors such as alcohol, aflatoxin, and early-onset HCC in hepatitis B virus infection contribute to the burden of HCC in Latin America. Interventions to increase screening coverage, expand healthcare access, and implement continuing medical training are key challenges to be overcome.
\end{abstract}

Hepatocellular carcinoma (HCC) accounts for 75 to $85 \%$ of all liver cancers, and carries a high burden in terms of incidence and mortality worldwide. Cholangiocarcinoma represents around $15 \%$, and other subtypes of liver cancers are even rarer. Generally, global statistics report data on liver cancer, without discriminating the histologic subtype. ${ }^{1}$

In 2016, there were over 1 million cases of liver cancer worldwide and 800,000 deaths. ${ }^{1}$ From 1990 to 2016, the incidence of liver cancer increased by $114 \%$ with a standardized incidence ratio of $0.34 \%$ per year in this period. ${ }^{2}$ In the United States, liver cancer diagnosis increased at a higher rate than any other malignancy in the past decade. ${ }^{3}$ The World Health Organization estimates that more than 1 million patients will die of this neoplasia in $2030 .^{4}$

The incidence of liver cancer varies significantly across different regions because of the varying prevalence of underlying risk factors. The highest incidence is observed in East Asia with an age-standardized incidence rate of 34.1 per 100,000 , followed by Asia-Pacific (22.9 per 100,000), South-East Asia (11.8 per 100,000), and Central sub-Saharan Africa (10.3 per $100,000)$. On the other hand, North America presents an incidence of 7.1 per 100,000 and Western Europe 7.4 per $100,000 .^{2}$ Similarly, the age-standardized mortality rates are highest in Eastern Asia (16.0 per 100,000) followed by Northern Africa (13.9 per 100,000) and Eastern Asia (13.2 per 100,000). ${ }^{5}$ Incidence and mortality are numerically close across different regions, which reflects the high lethality of this neoplasia. Indeed, this is explained by the significant proportion of patients with HCC who are diagnosed at advanced stage or will develop disease recurrence after locoregional treatments.

The most frequent etiologies are chronic infection by hepatitis B (HBV) or C viruses (HCV) and alcohol intake. Notably, an increasing trend in the prevalence of nonalcoholic fatty liver disease (NAFLD) associated with an increasing prevalence of 
obesity, diabetes mellitus, and metabolic syndrome is leading to changes in the geographic distribution of HCC, mainly in Western countries. ${ }^{6}$ This explains why a more pronounced increase in incidence is being observed in countries with favorable sociodemographic indicators. On the contrary, chronic infection by HBV is the main cause of HCC in high-prevalence countries such as China, while HCV still represents the main cause of HCC in Japan, Europe, and North America. ${ }^{7}$

The implementation of effective antiviral therapy with the direct-acting antiviral (DAA) drugs will potentially impact positively on reducing the global incidence of HCV-related HCC, although some issues regarding the risk of recurrence after local treatments are still being debated. ${ }^{8} \mathrm{HBV}$ vaccination has also been shown to significantly reduce the incidence of HCC, demonstrating that mortality can be prevented by controlling and eradicating the causative factors. ${ }^{9}$ Taken together, these findings support the prediction that HCC epidemiology is shifting from an infectious background to a disease primarily associated with fatty liver disease.

Having briefly contextualized the global landscape, we aim to describe the current scenario and future trends of HCC in Latin America, focusing on the main risk factors, surveillance, and particularities of HCC epidemiology in this region.

\section{Latin America-Structural Challenges}

Latin America is composed of 20 countries, representing almost $13 \%$ of the Earth's land surface area with an estimated population of more than 639 million. Latin America presents cultural and demographic heterogeneity and also a remarkable wealth disparity. Some Latin American countries account for the highest indicators of social and economic inequality. ${ }^{10}$ There are significant inequities between urban and rural areas, some of which are remote and lack access to healthcare, even in primary needs. Countries that rank lower in human development index, ${ }^{11}$ such as Haiti, Honduras, Nicaragua, and Bolivia, suffer from lack of human and technology resources, which explains the paucity of health data from many of them.

Many Latin American zones have experienced an intense urbanization process over the last 50 years. Today, approximately $80 \%$ of the region's population lives in cities. However, urbanization is high concentrated. Only Mexico and Brazil have more than a dozen cities with over a million inhabitants, while Uruguay and Paraguay do not have more than two cities with a population of more than a million. Despite the rates of urbanization, ineffective urban planning models prevent the implementation of a comprehensive health access in many urban centers. Even within urbanized areas, center-periphery disparities are notable. ${ }^{12}$

Overall, Latin American countries have improved the amount of investments in healthcare in the past two decades (7.3\% of the gross domestic product in 2014 vs. 6.3\% in 1995), but still below the average of the Organization for Economic Co-operation and Development (12.3\%). ${ }^{12}$ Also, different systems of health coverage coexist in many countries, ranging from private to public models. As a consequence, healthcare access, development, and incorporation of new technologies are heterogeneous between different countries and also across different regions in the same country. The epidemiology of HCC in Latin America mirrors important aspects of the healthcare organization and may be an indicator of defective points such as screening coverage, early identification of at-risk populations, primary prevention, early diagnosis, and expansion of access to proper treatment.

\section{HCC Incidence and Mortality in Latin America}

In 2018 , there were around 840,000 cases of liver cancer, of which $4.6 \%$ (representing around 38,400 cases) occurred in Latin America. Data from GLOBOCAN 2018 point out an agestandardized incidence rate in different Latin American countries (considering both sex and age) that ranges from less than 2.9 to more than 6.6 cases per 100,000 . According to region and sex, in Central America the male/female incidence is 6.7/6.0 per 100,000 ; in South America, it is 5.8/3.5 per 100,000; and North America (Mexico) presents $10.1 / 3.4$ per $100,000 .^{5}$

In terms of global mortality, there were an estimated 762,000 deaths due to liver cancer in 2018 . The proportion of cases in Latin America is 4.7\% (representing around 36,000 cases). The mortality in different countries ranges from less than 2.8 to more than 6.3 per 100,000 (-Fig. 1). ${ }^{5}$ In accordance with what is observed in other parts of the world, the ratio between incidence and mortality is close to 1 , confirming the high lethality of liver cancer in the region (-Table $\mathbf{1}$ ).

There is a paucity of data regarding HCC survival and longterm follow-up in Latin America. However, reports are consistent with a high proportion of advanced stage at diagnosis (20-41\%), a significant rate of symptomatic disease at first presentation (around 50\%), and a better survival in patients under screening treated with curative intent (around $30 \%$ at 5 years). ${ }^{13-15}$

\section{Burden of Risk Factors for HCC in Latin America}

Cirrhosis is the main risk factor for HCC regardless of the underlying etiology. It is estimated that one-third of patients with cirrhosis will develop HCC during their lifetime. ${ }^{16}$

The BRIDGE study, which was a multiregional longitudinal study that aimed to report the real-life management of more than 18,000 HCC patients, showed that the most common risk factor in all areas is HCV infection, except in China, South Korea, and Taiwan where HBV was the predominant etiology. ${ }^{17}$ This study did not report data from Latin America. Indeed, there is a paucity of comprehensive information regarding demographic characteristics and occurrence of risk factors in this region.

In 2017, Debes et $\mathrm{al}^{15}$ reported a multinational cohort study involving 14 medical centers of six different countries from South America, which aimed to identify the demographic features and risk factors associated with HCC. This study included 1,336 patients between 2005 and 2015. Brazil accounted for $40 \%$ of the cohort $(n=540)$, followed by Argentina $(19 \% ; n=251)$, Colombia (18\%; $n=239)$, Peru $(16 \% ; n=220)$, 


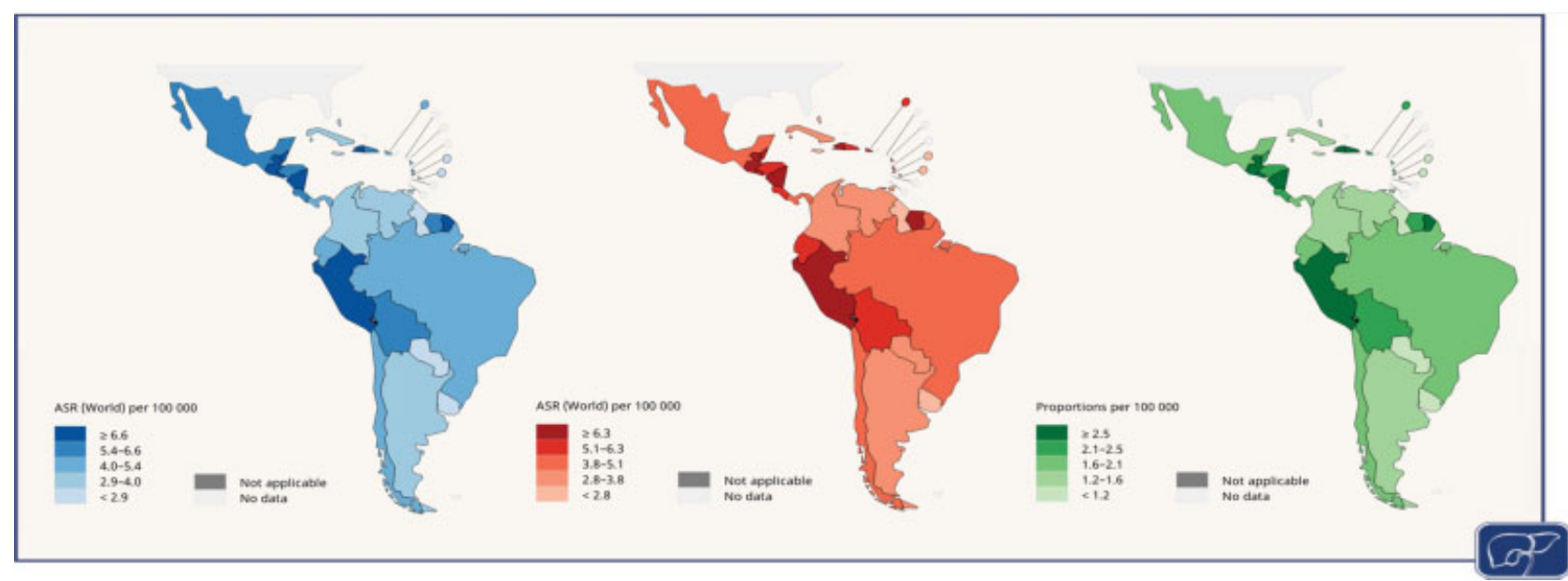

Fig. 1 Epidemiology of liver cancer in Latin America. Data are from the International Agency for Research on Cancer (https://gco.iarc.fr/today/ home, accessed August 15, 2019). (A) Estimated age-standardized incidence rates in 2018; (B) estimated age-standardized mortality rates in 2018; (c) estimated number of prevalent cases (1 year) as a proportion in 2018. (ASR: age-standardized rate per 100,000 population).

Table 1 Estimated number of new cases and deaths due to liver cancer in 2018 (both sexes and all ages)

\begin{tabular}{|l|l|l|l|l|}
\hline Regions & $\begin{array}{l}\text { New } \\
\text { cases }\end{array}$ & $\begin{array}{l}\text { ASR } \\
\text { (world) }\end{array}$ & Deaths & $\begin{array}{l}\text { ASR } \\
\text { (world) }\end{array}$ \\
\hline $\begin{array}{l}\text { Latin America } \\
\text { and the } \\
\text { Caribbean }\end{array}$ & 38,400 & 5.0 & 36,436 & 4.7 \\
\hline Asia & 609,596 & 11.4 & 566,269 & 10.5 \\
\hline Europe & 82,466 & 5.1 & 77,375 & 4.4 \\
\hline Africa & 69,779 & 8.4 & 63,562 & 8.3 \\
\hline North America & 41,851 & 6.6 & 34,339 & 4.8 \\
\hline Oceania & 3,988 & 6.9 & 3,650 & 5.8 \\
\hline
\end{tabular}

Abbreviation: ASR, age-standardized rates per 100,000.

Note: Data are from the International Agency for Research on Cancer (accessed August 14, 2019).

Ecuador $(5 \%, n=65)$, and Uruguay $(2 \%, n=21)$. The majority of patients were male (68\%) and the median age was 64 years. HCV infection was the most frequent risk factor, representing $48 \%$ of the cases. Alcoholic cirrhosis was the second leading cause with $22 \%$, followed by HBV infection in $14 \%$, NAFLD in $9 \%$, and other causes in $8 \%$ (cryptogenic cirrhosis, hemochromatosis, autoimmune liver disease, $\mathrm{HBV} / \mathrm{HCV}$ coinfection, schistosomiasis, and primary biliary cirrhosis). Besides, alcohol intake was associated with $29 \%$ of $\mathrm{HCV}$ and with $18 \%$ of HBV-related cases.

In all countries, HCV and alcohol abuse were the main common risk factors. The only exception was Peru. In this country, HBV was the leading cause, comprising $34 \%$ of cases. In fact, the majority of the HCC cases related to HBV infection in Latin America are reported from Peru and Brazil (34 and $38 \%$, respectively), followed by Argentina (16\%), Colombia (7\%), Ecuador (7\%), and Uruguay (2\%). Almost half of HBVassociated cases in Peru were from the Amazonian region, ${ }^{18}$ which comprehends a large area of Northwest Brazil, Peru, Venezuela, Colombia, and Ecuador. HBV genotype $\mathrm{F}$ is the most prevalent in Amerindian population ${ }^{19}$ and also in countries from Central ${ }^{20}$ and South America ${ }^{21}$ that cover the Amazonian region. This genotype is reported to be associated with early onset of HCC in Alaska natives. ${ }^{21}$ Notably, $38 \%$ of the HCC patients with HBV in Latin America were diagnosed before the age of 50 years with a median age of 58 years. In patients with HCV, 94\% were diagnosed after age 50 years, with a median age of 63 years. NAFLD patients were diagnosed with a median age of 67 years, and among patients with alcoholic cirrhosis, the median age at diagnosis was 68 years. $^{15}$

In a national Brazilian survey including 29 centers and 1,405 patients between 2004 and 2009, HCV infection was the main etiology (54\%). HBV was found in $16 \%$ and alcohol in $14 \%$. Among HBV cases, $14.5 \%$ were associated with HCV coinfection and $3.4 \%$ with hepatitis delta virus. Distinct prevalences of HCC were observed across different Brazilian regions, probably due to differing prevalence of HBV (higher in Amazonian region). ${ }^{22}$ In 1997, another survey had showed that HBV was the most common cause of liver disease in patients with HCC at that time in Brazil. ${ }^{23}$ This suggests temporal changes in the distribution of risk factors over the past two decades. Similar changes are also observed in global data: the proportion of HCV increased from 37.1 to $40.1 \%$ between 1990 and 2016 in Western Europe, while alcohol consumption decreased from 39.3 to $34.5 \%$ during the same period. $^{2}$

The incidence of HCV-related HCC is expected to decrease due to the incorporation of DAAs. ${ }^{24}$ In Latin America, a prospective multinational cohort that followed 1,400 patients treated with DAA reported an incidence of de novo HCC of $2 \%$ at 12 months and $4 \%$ at 24 months. In this cohort, most of the patients presented F3 or F4 fibrosis and around $28 \%$ had clinically significant portal hypertension. Achieving sustained virologic response resulted in a relative HCC risk reduction of $73 \%$, while failure to achieve it was independently associated with de novo HCC. However, patients with F4 fibrosis showed a cumulative incidence of 3 and $6 \%$ at 12 and 24 months, which suggests that advanced liver disease demands continuous surveillance even in cases with sustained virologic response. ${ }^{25}$ 
Conflicting information regarding the impact of DAA regimens on the occurrence of de novo HCC are being published in other parts of the world. ${ }^{8,26}$ In this regards, Latin American initiatives, as mentioned earlier, are crucial in gathering evidence to future research on this topic.

In sum, the available evidence supports that the current scenario in Latin America is similar to what is observed in the United States, Western Europe, and Japan regarding the predominance of HCV and alcohol intake as the main etiologies. However, some regional peculiarities are remarkable, as exemplified by the occurrence of HBV-related HCC in Peru.

\section{NAFLD/NASH: Current Trends Worldwide and in Latin America}

Nonalcoholic fatty liver disease and nonalcoholic steatohepatitis (NASH) are recognized as important causes of liver disease and HCC. In the United States, around 6 million people have NASH and it represents a leading indication for liver transplantation. ${ }^{27}$ About 10 to $30 \%$ of NAFLD cases may progress to cirrhosis, and HCC might appear even in the absence of significant liver fibrosis in these patients. ${ }^{28}$ Another relevant issue in this context is the likely overlap with alcohol, and there is a need to better clarify the coexistence of alcohol and fatty liver disease in some settings.

Patients with NASH seem to present a lower risk of HCC than patients with HCV-related liver disease. In a large cohort study with NASH patients in the United States, the incidence of HCC was 1.06 per 100 person-years. ${ }^{29}$ NAFLD probably carries a lower risk of liver cancer than patients with NASH cirrhosis, but because NAFLD affects a huge number of people around the world, this condition is a relevant factor. Patients with noncirrhotic NAFLD have an incidence of HCC of 0.008 per 100 person-years. $^{29}$

The impact of NAFLD/NASH on HCC epidemiology is likely to be underestimated due to heterogenous definitions, differing proportions of patients with metabolic syndrome, and referral bias. ${ }^{30}$ Other adjuvant features of metabolic syndrome, such as diabetes and obesity, are also considered emergent risk factors for HCC.

In Latin America, obesity and overweight have become major challenges. Around $57 \%$ of the adult population (54\% of men and $70 \%$ of women) is overweight and $19 \%$ (14.6\% of men and $24 \%$ of women) is obese. The highest prevalence of obesity is found in El Salvador (33.0\%) and Paraguay (30.1\%) for women, and Uruguay (23.3\%) and Chile (22.0\%) for men. ${ }^{31}$ Additionally, NAFLD is highly prevalent in South America (31\%), comparing to an estimation of $25 \%$ in the adult population globally. ${ }^{32}$

In 2016, a Brazilian study aimed to evaluate clinical characteristics of patients with HCC and NASH included 110 patients. In this cohort, obesity was observed in $52.7 \%$ of cases, diabetes in $73.6 \%$, dyslipidemia in $41.0 \%$, and metabolic syndrome in $57.2 \%$. Fifty-two (47.2\%) patients had histological diagnosis of HCC. Among those 52 patients, NASH with cirrhosis was found in 32 (61.5\%), NASH with fibrosis grades 1 to 3 in 14 (27\%), and NASH without fibrosis in $2(3.8 \%)$ patients. In four (7.7\%) patients, HCC was the only histological diagnosis, with a clinical diagnosis of NAFLD. ${ }^{33}$
A longitudinal cohort from Argentina included 708 HCC patients diagnosed between 2009 and 2015 and showed that NAFLD was the third cause of HCC, representing $11.4 \%$ of the cases (the first was HCV in $37 \%$, followed by alcoholic liver disease in $20.8 \%$ ). During the study period, there was a sixfold increase in the incidence of NAFLD-related HCC, with $4.3 \%$ of NAFLD-related HCC in 2009 and $25.6 \%$ in 2015. ${ }^{34}$

In the same sense, a study involving two hospitals from Chile with 288 patients with HCC reported an increase in NAFLD and a decrease in alcoholic liver disease. Notably, the leading cause of liver disease in this cohort was NAFLD (38.8\%), followed by HCV (25.2\%). ${ }^{35}$

Unpublished data from Brazilian registries of 508 liver transplantations in Hospital das Clínicas da Faculdade de Medicina da Universidade de São Paulo reported an increase in the proportion of NASH as the etiology of liver disease in patients submitted to liver transplantation. Between 2007 and 2009, 4 (0.5\%) were attributed to NASH and between 2016 and 2018, there were 25 cases (3.2\%). However, surgical series may overestimate the occurrence of HCC in noncirrhotic NASH liver, as these patients are more likely to be considered for resection than patients with the same tumor burden but with poor liver function. Besides, NASH requires histological confirmation. This is an important consideration when analyzing epidemiological data on this topic.

To sum up, there is a global concern regarding a potential increasing in the number of patients with NAFLD- and NASHrelated HCC. This is particularly important in Latin America, given that NAFLD is highly prevalent in this region. Up till now, there is no strong data from the region supporting that NAFLD/NASH is a leading cause of HCC. However, the initial reports mentioned in this section warrant continued exploration and data collection, with detailed risk factor exposure and histological evaluation. Importantly, alcohol intake in studied populations should be registered to rule out a biased conclusion.

\section{Regional Particularities: Early Onset of HBV- Related HCC and Molecular Profile of Aflatoxin-Related HCC}

Despite the fact that the general context of HCC in Latin America shares similarities with many Western countries, some groups have described patterns of HCC occurrence with specific characteristics in different Latin American regions.

This is the case for an unusual form of HCC affecting children, adolescents, and young adults described in a retrospective series of 232 HCC patients submitted to surgical resection in Peru between 1990 and 2006. The median age of this cohort was 36 years, and $44.2 \%$ were associated with chronic HBV infection (not including those with resolved infection: HBsAg negative and anti-HBc positive). Only $16.3 \%$ of them had cirrhosis and the median AFP level was $5,467 \mathrm{ng} / \mathrm{mL}^{36}$ This lower incidence of cirrhosis, when comparing to data from other Western regions, ${ }^{37}$ probably relies on the early onset and the etiologic background, with a predominance of HBV and only $5 \%$ related to $\mathrm{HCV}$ infection. ${ }^{36}$ Another study in the Peruvian population with 1,541 patients described a bimodal 
incidence of HCC, with a first peak of incidence around the age of 25 years and a second one at the age of 64 years. $^{38}$

The retrospective nature of the data prevents any definitive conclusion and selection bias may affect interpretation. However, this result suggests a particular behavior in terms of clinical course and an unusual HCC population, mirroring data from sub-Saharan Africa and Taiwan with HBV infection during birth or immediately after. ${ }^{39}$

To analyze whether genetic variations exist between younger and older HCC patients, Marchio et $\mathrm{al}^{40}$ performed a study involving 80 Peruvian patients, 41 diagnosed under 40 years old, and 39 diagnosed over 40 years old. Mutations in the Wnt pathway were more frequent among younger patients compared with patients older than 40 years and AXIN1 mutations were more frequent in women than in men. The authors also described a predominance of genetic alterations represented by insertions/deletion.

In a subsequent analysis, another molecular study including 65 Peruvian patients was conducted. The authors found HBV DNA in the tumor and/or matched nontumor tissue in $81.5 \%$, predominantly among younger patients. Besides, a low viral HBV DNA burden among younger patients was also found, which challenges the hypothesis that associates high HBV DNA load with earlier tumor development. ${ }^{41}$

Although these findings were not validated in other Latin American cohorts, they suggest that key aspects in the hepatocarcinogenesis might be different to that observed in other parts of the world. In this regard, additional studies are required to support the implementation of strategies on prevention (mainly expanding HBV vaccination in Amazonian region), diagnosis, and treatment for HCC patients who share these molecular features. ${ }^{41}$

Latin America compromises 3\% of the global burden of aflatoxin-related $\mathrm{HCC}^{42}$ Aflatoxins are produced by the fungi Aspergillus parasiticus and Aspergillus flavus, which colonize food commodities such as groundnuts and tree nuts in tropical regions of the world. Aflatoxin exposure in food is a well-documented risk factor for HCC, presenting most often in individuals with chronic HBV infection, with up to 30 times greater risk than aflatoxin exposure without HBV. ${ }^{43,44}$ Aflatoxin exposure predominantly affects rural populations more than urbanized populations. ${ }^{45}$

Liu et $\mathrm{al}^{42}$ conducted a quantitative cancer risk assessment that approached aflatoxin exposure and HBV prevalence to estimate the global burden of aflatoxin-related HCC. The estimation in Latin America is 6.0 to 15.0 and 0.20 to 0.50 aflatoxin-induced HCC cases per year per 100,000 people in HBsAg-positive and HBsAg-negative patients, respectively. This estimation was based only on data from Brazil, Mexico, and Argentina; therefore, it is not fully representative of the entire Latin America. This indicates a higher incidence compared with North America (0.08-0.3 and 0.003-0.01 per 100,000) and Europe (0-1.2 and 0-0.04 per 100,000), but with a better general outlook compared with Africa (3.0-54.0 and 0.1-1.8 per 100,000) and Southeast Asia (9.0-30.0 and $0.30-1.00$ per 100,000$)$.

Nogueira et $\mathrm{al}^{46}$ assessed the frequency of TP53 249Ser mutation in 74 HCC patients submitted to resection or transplantation in a Brazilian cohort. This mutation is a molecular evidence of aflatoxin-related carcinogenesis and there is a strong correlation between this mutation and dietary exposure of aflatoxin. In this study, the 249-Ser mutation was found in $28 \%$ of cases, suggesting that aflatoxin is a potential risk factor in the studied population. Moreover, this mutation was correlated with larger tumors and poorly differentiated histology.

\section{Screening for HCC in Latin America}

Screening is widely applied, although evidence of positive impact on reducing mortality is scarce. A randomized controlled trial that supports screening for HCC was performed in China with more than 18,000 patients and demonstrated a $37 \%$ reduction in risk of death in screened patients with abdominal ultrasound and $\alpha$-fetoprotein (AFP) test performed every 6 months. ${ }^{47}$ However, this study included only the HBV-infected population, study adherence was poor, and the trial is limited by the use of randomization by clusters.

A validation trial in other parts of the world, such as the United States, Europe, or Latin America is unfeasible, and its implementation would be ethically questionable. Therefore, ultrasonography every 6 months is a part of the routine evaluation of patients with chronic liver disease and high risk of HCC, and this practice is endorsed by the current clinical guidelines. ${ }^{48}$ The role of AFP as a surveillance tool is not well defined, mainly because varying levels of AFP levels might reflect activity of the underlying liver disease ${ }^{49}$ and also because only a small proportion of early-stage tumors show elevated AFP levels. ${ }^{50}$ Abdominal ultrasound has several advantages including low cost, easy availability, and safety. These features enable ultrasound to be applicable in regions with different socioeconomic contexts.

The implementation of surveillance programs with a significant rate of early detection was reported in a prospective Brazilian study with 884 cirrhotic patients. ParanaguáVezozzo et $\mathrm{al}^{51}$ characterized a long-term follow-up of patients who were submitted to at least one annual liver ultrasonography and a serum AFP measurement. During the study period (1998-2008), 72 (8.1\%) patients developed HCC with an annual incidence of $2.9 \%$. Of these 72 patients, around $80 \%$ were diagnosed with early stage, which allowed curative-intended treatments in the majority of the cases.

In a Latin American multinational retrospective study of incident HCC cases, there were significant differences in the proportion of patients diagnosed in each of the Barcelona Clinic Liver Cancer (BCLC) stages between patients who were enrolled in screening programs $(n=102)$ and those with incidental diagnosis $(n=86)$. In the former, $69.6 \%$ were diagnosed with BCLC-A stage, while in the latter, only $39.5 \%$ were BCLC-A. Consequently, more patients had BCLC-C and -D in the nonscreened group (18.6 vs. 8.0\%). ${ }^{52}$ Another cohort corroborated that individuals who attended ultrasound surveillance with a frequency of at least every 6 months had a higher probability of being diagnosed with early-stage tumors. ${ }^{53}$ 
Table 2 Studies from Latin America approaching risk factors and/or screening coverage

\begin{tabular}{|c|c|c|c|c|c|}
\hline & Population & Period & Risk factors & Methodology & $\begin{array}{l}\text { Diagnosis under } \\
\text { screening }\end{array}$ \\
\hline Debes et $\mathrm{al}^{15}$ & $\begin{array}{l}N=1,336 \\
\text { Brazil, Argentina, } \\
\text { Colombia, Ecuador, } \\
\text { Peru, and Uruguay }\end{array}$ & 2005-2015 & $\begin{array}{l}\text { HCV: } 48 \% \\
\text { HBV: } 22 \% \\
\text { Alcohol: } 14 \% \\
\text { NAFLD/NASH: } 9 \%\end{array}$ & $\begin{array}{l}\text { Retrospective } \\
\text { multicentric study }\end{array}$ & $\begin{array}{l}47 \% \text { diagnosed } \\
\text { during screening }\end{array}$ \\
\hline Bertani el al ${ }^{38}$ & $\begin{array}{l}N=1,541 \\
\text { Peru }\end{array}$ & 1997-2010 & $\begin{array}{l}\text { HCV: } 4.7 \% \\
\text { HBV: } 50.1 \% \\
\text { HCV + HBV: } 1.4 \%\end{array}$ & $\begin{array}{l}\text { Retrospective } \\
\text { multicentric study }\end{array}$ & Not reported \\
\hline Carrilho et $a^{22}$ & $\begin{array}{l}N=1,405 \\
\text { Brazil }\end{array}$ & 2004-2009 & $\begin{array}{l}\text { HCV: } 54 \% \\
\text { HBV: } 16 \% \\
\text { Alcohol: } 14 \% \\
\text { NASH/NAFLD: } 3 \%\end{array}$ & $\begin{array}{l}\text { Retrospective } \\
\text { multicentric study }\end{array}$ & Not reported \\
\hline Fassio et $\mathrm{al}^{52}$ & $\begin{array}{l}N=240 \\
\text { Brazil, Argentina, } \\
\text { Colombia, Chile, } \\
\text { Uruguay, and } \\
\text { Venezuela }\end{array}$ & 2007-2009 & $\begin{array}{l}\text { HCV: } 30.8 \% \text { Alcohol: } 20.4 \% \\
\text { HBV: } 10.8 \% \\
\text { HCV + alcohol: } 5.8 \%\end{array}$ & $\begin{array}{l}\text { Prospective } \\
\text { multicentric study }\end{array}$ & $\begin{array}{l}\text { 54\% diagnosed } \\
\text { during surveillance }\end{array}$ \\
\hline Kikuchi et al ${ }^{13}$ & $\begin{array}{l}N=364 \\
\text { Brazil }\end{array}$ & 2010-2012 & $\begin{array}{l}\text { HCV: } 55 \% \\
\text { HBV: } 13 \% \\
\text { Alcohol: } 16 \% \\
\text { NASH: } 9 \%\end{array}$ & $\begin{array}{l}\text { Retrospective } \\
\text { multicentric study }\end{array}$ & $\begin{array}{l}65 \% \text { diagnosed } \\
\text { during screening }\end{array}$ \\
\hline Piñero et al $^{14}$ & $\begin{array}{l}N=708 \\
\text { Argentina }\end{array}$ & 2009-2016 & $\begin{array}{l}\text { HCV: } 37 \% \\
\text { Alcohol: } 20.8 \% \\
\text { NASH/NAFLD: } 11.4 \% \\
\text { HBV: } 5.4 \%\end{array}$ & Multicentric study & $\begin{array}{l}58.1 \% \text { diagnosed } \\
\text { during screening }\end{array}$ \\
\hline
\end{tabular}

Abbreviations: HBV, hepatitis B virus; HCC, hepatocellular carcinoma; HCV, hepatitis C virus; NAFLD, nonalcoholic fatty liver disease; NASH, nonalcoholic steatohepatitis.

In terms of ultrasonography accuracy for HCC detection, a study performed in Argentina included 643 cirrhotic patients on liver transplantation waiting-list. In this study, the sensitivity was $33 \%$ and specificity was $99 \%{ }^{54}$ These results are in line with a recent meta-analysis that showed a sensitivity of $45 \%$ for detection of early HCC with a specificity of $84 \% .55$

There is no large study analyzing the coverage of ultrasound screening for early detection of HCC, mainly in remote areas of Latin America. The proportion of patients diagnosed with an incidental HCC outside a structured surveillance program is over $50 \%{ }^{15}$ and it is probably higher in unreported areas. Most of the data available come from academic institutions, in which patient care and adherence tend to be broader (-Table 2 ). As a consequence, there is likely to be an insufficient coverage and a significant rate of underreported advanced stage at initial presentation.

\section{Adherence to Clinical Practice Guidelines in Latin America: from Diagnosis to Treatment}

Adherence to guidelines is hampered by the heterogeneity in available resources, the unequal structure of healthcare systems, and imbalances in the geographical distribution of reference centers with expertise in HCC. The reality in these centers is further discussed in this section, but this may not be representative of the whole picture of Latin America.

Regarding diagnostic procedures, noninvasive imaging diagnosis of HCC in patients with cirrhosis and typical radio- logical hallmarks are accepted since $2001^{56}$ and endorsed by clinical practice guidelines. ${ }^{48,57}$ Both computed tomography and magnetic resonance have a good accuracy in detecting HCC according to the noninvasive diagnostic criteria, ${ }^{48,57}$ although false-positive findings are described. A multinational Latin American study with 422 HCC patients submitted to liver transplantation reported that only 18 patients did not had confirmed HCC in the explanted liver, showing a low rate of disparity between radiologic and histologic findings. ${ }^{58}$

Improvement in diagnostic accuracy, especially in the detection of small and potentially curable lesions, is under active debate worldwide. ${ }^{59}$ The use of Li-RADS criteria integrates features not related to tumor enhancement, such as capsule and growth over time. This adds more complexity in clinical decision making, particularly in intermediate categories (Li-RADS 3 and 4), which can represent a potential source of misinterpretation of the system and low adherence to treatment algorithms worldwide.

Several staging systems have been designed to provide prognostic information and help clinical decision. The BCLC staging system ${ }^{6}$ is endorsed by practical guidelines, including the Latin America Association for the Study of the Liver. ${ }^{60}$ This classification has been externally validated in different clinical settings and is frequently updated to incorporate the ongoing novelties and concepts. ${ }^{61,62}$

The BRIDGE study ${ }^{17}$ documented marked heterogeneity of treatment approaches across different regions and countries. Accordingly, regional differences, access, and costs may lead to 
a similar context in Latin America. Transarterial chemoembolization was the most frequent used and transplantation was the less used modality in a multicenter South American cohort, while ablation, resection, and systemic therapy varied among countries.

The adherence to the BCLC system varies from 49 to $71 \%$ in different publications. ${ }^{63,64}$ A multicenter study performed by Piñero et $\mathrm{al}^{14}$ in Argentina, involving 14 hospitals and 708 patients, evaluated the adherence to the BCLC system. The overall adherence was 53\% and the lowest adherence was reported in BCLC-C patients (29.8\%).

Accordingly, a Brazilian retrospective study also reported an adherence to the BCLC staging system of 52\% in 364 patients between 2010 and 2012. The rate of adherence varied in different stages: BCLC-0, 33\%; BCLC-A, 45\%; BCLC-B, 78\%; BCLC-C, 35\%; and BCLC-D, 67\%. In early and very early stages, adherence impacted positively on overall survival and no differences were observed between adherent and nonadherent patients in BCLC-B and C stages. ${ }^{13}$

The selection of patients for liver transplantation is key to improve outcomes in the subset of patients with liver-only disease. Unfortunately, lack of access and disparities in health coverage are barriers in the development of liver transplantation programs in Latin America. While some countries, such as Argentina, Brazil, Colombia, Peru, Mexico, and Chile, dispose of consolidated programs, lower middle-income countries, such as Honduras, Nicaragua, and Guatemala, are not able to maintain liver transplantation programs. ${ }^{65}$ Even the countries with a large number of liver transplantations face difficulties regarding intraregional disparity and geographic distances. The need for a more structure health system and international cooperation are crucial in Latin America, together with initiatives to educate the population and increase awareness of organ donation in the regions with well-established transplantation activity.

This scenario will probably become more challenging, as new DAA therapy is shown to reduce the indications for liver transplantation due to $\mathrm{HCV}^{66}$ and less strict criteria (beyond Milan) are being studied to expand the indication in HCC patients.

According to data from Latin American countries with established transplantation programs, HCC accounts for 11 to $17 \%$ of the liver transplantations in the region. ${ }^{67-69}$ Milan criteria are the most frequent use and around 75 to $90 \%$ of the reported cohorts are in these criteria. ${ }^{67-70}$ The posttransplantation recurrence rate in a large Brazilian ${ }^{71}$ cohort was $8 \%$, similar to what is described in the literature worldwide. ${ }^{72}$

Systemic therapies are recommended for BCLC-C patients or those who progressed on or have contraindications to locoregional modalities. The first agent that improved survival in this group was sorafenib. This drug was incorporated in the clinical practice worldwide in 2008, after the publication of two pivotal trials. ${ }^{73,74}$ Although costs are an important issue, sorafenib is currently adopted in many Latin American countries. In a multicenter study with sorafenib-treated patients from Argentina, Brazil, Colombia, Ecuador, and Peru, 80\% received sorafenib as the upfront treatment once most of the patients had BCLC-B and C stages.
The median survival of this cohort was 8 months, ${ }^{75}$ inferior to what was observed in the SHARP trial. ${ }^{73}$ Low survival in patients under systemic treatment with sorafenib was also observed in other Latin American cohorts. ${ }^{76,77}$ Socioeconomic differences, delay in starting treatment, administrative and organizational deficiencies, and inclusion of subgroups of patients with no strong evidence (for example, liver dysfunction and BCLC-D stage) are possible reasons for the poor survival.

In 2017, a second-line agent, regorafenib, was approved based on positive results of a phase III trial. ${ }^{78}$ This agent received local approval in Latin American countries such as in Brazil, Colombia, Argentina, and Mexico, but is not yet widely included in the daily practice in public health. In the last 2 years, two additional agents (cabozantinib ${ }^{79}$ and ramucirumab $^{80}$ ) also demonstrated survival improvement in phase III studies. However, due to delays in drug approval by local regulatory bodies, most Latin American countries still face difficulties in offering novel drugs to HCC patients. Use of cytotoxic chemotherapy (mainly doxorubicin and fluoropyrimidine combinations) was reported in patients after sorafenib exposure with disappointing overall survival in a Brazilian experience. ${ }^{81}$ This scenario highlights that better outcomes with systemic treatment in HCC require integration of financial and organizational factors with the application of clinical criteria grounded on the best evidence available.

\section{Challenges and Future Perspectives}

In this review, we described the available data on HCC epidemiology in Latin America comparing to global trends and the changing landscape in the management of this malignancy. Globally, as well as in Latin America, HCC is a major health problem and one of the leading causes of cancer mortality.

The familiarity with the prevalence of risk factors and how they may change in the coming years should drive new programs directed to improve the rate of early-stage diagnosis. HCV still represents the main etiology associated with HCC. Interferon-free regimens for HCV provided high rates of cure; so, an effort to identify and treat HCV patients will surely impact positively on the incidence of HCC. HBV vaccination is an urgent need in some regions with high incidence. These actions should integrate the general population, medical professionals, academic institutions, and government agencies.

Strategies on how to screen patients with NAFLD/NASH is a matter of intense debate and study worldwide. The current focus is placed on trying to identify which group of patients with NAFLD/NASH without cirrhosis should be screened, and how the screening should be performed. ${ }^{30}$ As a region with a clear trend of increasing in NAFLD prevalence, Latin American centers should contribute to generating evidence on this issue.

Research, training, and scientific exchange are a driver for health care improvement, especially in the field of liver cancer. Medical education initiated in reference centers and disseminated to the primary healthcare system is paramount to improve primary prevention, implementation of comprehensive surveillance programs at high-risk patients, 
and access to treatment options supported by the best available evidence. Multinational initiatives and dedicated network groups between Latin American countries and integrated with centers in other parts of the world can overcome the inherent socioeconomic difficulties and provide better care to HCC patients.

\section{Main Concepts and Learning Points}

- Hepatocellular carcinoma is a major issue in Latin America. Improvements in health care access, surveillance, and continuing medical training are required.

- Increasing reports of liver cancer associated with fatty liver disease in Latin America mirror a trend observed in many Western countries.

- Viral hepatitis, alcohol, and aflatoxin remain predominant risk factors in Latin America.

- Multinational network efforts integrated with referral groups worldwide are paramount to delivering better care to hepatocellular carcinoma patients.

Conflicts of Interest

Dr. Leonardo da Fonseca reports personal fees from Bayer.

\section{References}

1 Fitzmaurice C, Akinyemiju TF, Al Lami FH, et al; Global Burden of Disease Cancer Collaboration. Global, regional, and national cancer incidence, mortality, years of life lost, years lived with disability, and disability-adjusted life-years for 29 cancer groups, 1990 to 2016: a systematic analysis for the global burden of disease study. JAMA Oncol 2018;4(11):1553-1568

2 Liu Z, Jiang Y, Yuan $\mathrm{H}$, et al. The trends in incidence of primary liver cancer caused by specific etiologies: results from the Global Burden of Disease Study 2016 and implications for liver cancer prevention. J Hepatol 2019;70(04):674-683

3 Ryerson AB, Eheman CR, Altekruse SF, et al. Annual Report to the Nation on the Status of Cancer, 1975-2012, featuring the increasing incidence of liver cancer. Cancer 2016;122(09):1312-1337

4 Mathers CD, Loncar D. Projections of global mortality and burden of disease from 2002 to 2030. PLoS Med 2006;3(11):e442

5 Bray F, Ferlay J, Soerjomataram I, Siegel RL, Torre LA, Jemal A. Global cancer statistics 2018: GLOBOCAN estimates of incidence and mortality worldwide for 36 cancers in 185 countries. CA Cancer J Clin 2018;68(06):394-424

6 Forner A, Reig M, Bruix J. Hepatocellular carcinoma. Lancet 2018; 391(10127):1301-1314

7 Bertuccio P, Turati F, Carioli G, et al. Global trends and predictions in hepatocellular carcinoma mortality. JHepatol 2017;67(02): 302-309

8 Reig M, Boix L, Mariño Z, Torres F, Forns X, Bruix J. Liver cancer emergence associated with antiviral treatment: an immune surveillance failure? Semin Liver Dis 2017;37(02):109-118

9 Chang M-H, You S-L, Chen C-J, et al; Taiwan Hepatoma Study Group. Long-term effects of hepatitis B immunization of infants in preventing liver cancer. Gastroenterology 2016;151(03):472-480.e1

10 Baten J, International Economic History Association. A History of the Global Economy: From 1500 to the Present. Cambridge University Press; 2016

11 Human Development Reports. Available at: http://hdr.undp.org/en/composite/HDI. Accessed August 13, 2019

12 Current health expenditure (\% of GDP) | Data. Available at: https://data.worldbank.org/indicator/SH.XPD.CHEX.GD.ZS. Accessed August 13, 2019
13 Kikuchi L, Chagas AL, Alencar RSSM, et al. Adherence to BCLC recommendations for the treatment of hepatocellular carcinoma: impact on survival according to stage. Clinics (São Paulo) 2017;72 (08):454-460

14 Piñero F, Marciano S, Fernández N, et al; Argentinean Association for the Study of Liver Diseases (A.A.E.E.H). Adherence to Barcelona Clinic Liver Cancer therapeutic algorithm for hepatocellular carcinoma in the daily practice: a multicenter cohort study from Argentina. Eur J Gastroenterol Hepatol 2018;30(04):376-383

15 Debes JD, Chan AJ, Balderramo D, et al. Hepatocellular carcinoma in South America: evaluation of risk factors, demographics and therapy. Liver Int 2018;38(01):136-143

16 Sangiovanni A, Prati GM, Fasani P, et al. The natural history of compensated cirrhosis due to hepatitis $C$ virus: A 17-year cohort study of 214 patients. Hepatology 2006;43(06):1303-1310

17 Park J-W, Chen M, Colombo M, et al. Global patterns of hepatocellular carcinoma management from diagnosis to death: the BRIDGE Study. Liver Int 2015;35(09):2155-2166

18 Chan AJ, Balderramo D, Kikuchi L, et al. Early age hepatocellular carcinoma associated with hepatitis B infection in South America. Clin Gastroenterol Hepatol 2017;15(10):1631-1632

19 Devesa M, Loureiro CL, Rivas Y, et al. Subgenotype diversity of hepatitis B virus American genotype $F$ in Amerindians from Venezuela and the general population of Colombia. J Med Virol 2008;80(01):20-26

20 Arauz-Ruiz P, Norder H, Visoná KA, Magnius LO. Genotype F prevails in HBV infected patients of Hispanic origin in Central America and may carry the precore stop mutant. JMed Virol 1997;51(04):305-312

21 Devesa M, Pujol FH. Hepatitis B virus genetic diversity in Latin America. Virus Res 2007;127(02):177-184

22 Carrilho FJ, Kikuchi L, Branco F, Goncalves CS, Mattos AA; Brazilian HCC Study Group. Clinical and epidemiological aspects of hepatocellular carcinoma in Brazil. Clinics (São Paulo) 2010;65(12): $1285-1290$

23 Gonçalves CS, Pereira FE, Gayotto LC. Hepatocellular carcinoma in Brazil: report of a national survey (Florianópolis, SC, 1995). Rev Inst Med Trop São Paulo 1997;39(03):165-170

24 Pawlotsky J-M, Negro F, Aghemo A, et al; European Association for the Study of the Liver. Electronic address: easloffice@easloffice. eu; European Association for the Study of the Liver. EASL recommendations on treatment of hepatitis C 2018. JHepatol 2018;69 (02):461-511

25 Piñero F, Mendizabal M, Ridruejo E, et al; LALREAN. Treatment with direct-acting antivirals for HCV decreases but does not eliminate the risk of hepatocellular carcinoma. Liver Int 2019; 39(06):1033-1043

26 Conti F, Buonfiglioli F, Scuteri A, et al. Early occurrence and recurrence of hepatocellular carcinoma in HCV-related cirrhosis treated with direct-acting antivirals. JHepatol 2016;65(04):727-733

27 Younossi ZM. Nonalcoholic fatty liver disease and nonalcoholic steatohepatitis: implications for liver transplantation. Liver Transpl 2018;24(02):166-170

28 LaBrecque DR, Abbas Z, Anania F, et al; Review Team; World Gastroenterology Organisation. World Gastroenterology Organisation global guidelines: nonalcoholic fatty liver disease and nonalcoholic steatohepatitis. JClin Gastroenterol 2014;48(06): 467-473

29 Kanwal F, Kramer JR, Mapakshi S, et al. Risk of hepatocellular cancer in patients with non-alcoholic fatty liver disease. Gastroenterology 2018;155(06):1828-1837.e2

30 Reig M, Gambato M, Man NK, et al. Should patients with NAFLD/NASH be surveyed for HCC? Transplantation 2019;103 (01):39-44

$31 \mathrm{Ng} \mathrm{M}$, Fleming T, Robinson M, et al. Global, regional, and national prevalence of overweight and obesity in children and adults during 1980-2013: a systematic analysis for the Global Burden of Disease Study 2013. Lancet 2014;384(9945):766-781 
32 Younossi ZM, Koenig AB, Abdelatif D, Fazel Y, Henry L, Wymer M. Global epidemiology of nonalcoholic fatty liver disease-Metaanalytic assessment of prevalence, incidence, and outcomes. Hepatology 2016;64(01):73-84

33 Cotrim HP, Oliveira CP, Coelho HSM, et al. Nonalcoholic steatohepatitis and hepatocellular carcinoma: Brazilian survey. Clinics (São Paulo) 2016;71(05):281-284

34 Piñero F, Pages J, Marciano S, et al. Fatty liver disease, an emerging etiology of hepatocellular carcinoma in Argentina. World J Hepatol 2018;10(01):41-50

35 Roblero J, Henríquez V, Torres F, et al. Non alcoholic fatty liver disease: main etiology of cirrhosis in patients with carcinoma hepatocellular in two hospitals of Santiago, Chile. Ann Hepatol 2018;17(06):1151 (abs 171)

36 Ruiz E, Sanchez J, Celis J, et al. Short and long-term results of liver resection for hepatocarcinoma in Peru: a Peruvian single center experience on 232 cases [in Spanish]. Rev Gastroenterol Peru 2007;27(03):223-237

37 Esnaola NF, Mirza N, Lauwers GY, et al. Comparison of clinicopathologic characteristics and outcomes after resection in patients with hepatocellular carcinoma treated in the United States, France, and Japan. Ann Surg 2003;238(05):711-719

38 Bertani S, Pineau P, Loli S, et al. An atypical age-specific pattern of hepatocellular carcinoma in Peru: a threat for Andean populations. PLoS One 2013;8(06):e67756

39 MacLachlan JH, Cowie BC. Hepatitis B virus epidemiology. Cold Spring Harb Perspect Med 2015;5(05):a021410

40 Marchio A, Bertani S, Rojas Rojas T, et al. A peculiar mutation spectrum emerging from young Peruvian patients with hepatocellular carcinoma. PLoS One 2014;9(12):e114912

41 Marchio A, Cerapio JP, Ruiz E, et al. Early-onset liver cancer in South America associates with low hepatitis B virus DNA burden. Sci Rep 2018;8(01):12031

42 Liu Y, Wu F. Global burden of aflatoxin-induced hepatocellular carcinoma: a risk assessment. Environ Health Perspect 2010;118 (06):818-824

43 Wild CP, Gong YY. Mycotoxins and human disease: a largely ignored global health issue. Carcinogenesis 2010;31(01):71-82

44 Groopman JD, Johnson D, Kensler TW. Aflatoxin and hepatitis B virus biomarkers: a paradigm for complex environmental exposures and cancer risk. Cancer Biomark 2005;1(01):5-14

45 Plymoth A, Viviani S, Hainaut P. Control of hepatocellular carcinoma through hepatitis B vaccination in areas of high endemicity: perspectives for global liver cancer prevention. Cancer Lett 2009; 286(01):15-21

46 Nogueira JA, Ono-Nita SK, Nita ME, et al. 249 TP53 mutation has high prevalence and is correlated with larger and poorly differentiated HCC in Brazilian patients. BMC Cancer 2009;9(01):204

47 Zhang B-H, Yang B-H, Tang Z-Y. Randomized controlled trial of screening for hepatocellular carcinoma. J Cancer Res Clin Oncol 2004;130(07):417-422

48 Galle PR, Forner A, Llovet JM, et al; European Association for the Study of the Liver. Electronic address: easloffice@easloffice.eu; European Association for the Study of the Liver. EASL Clinical Practice Guidelines: management of hepatocellular carcinoma. J Hepatol 2018;69(01):182-236

49 Di Bisceglie AM, Sterling RK, Chung RT, et al; HALT-C Trial Group. Serum alpha-fetoprotein levels in patients with advanced hepatitis C: results from the HALT-C Trial. JHepatol 2005;43(03): 434-441

50 Villanueva A, Minguez B, Forner A, Reig M, Llovet JM. Hepatocellular carcinoma: novel molecular approaches for diagnosis, prognosis, and therapy. Annu Rev Med 2010;61(01):317-328

51 Paranaguá-Vezozzo DC, Ono SK, Alvarado-Mora MV, et al. Epidemiology of HCC in Brazil: incidence and risk factors in a ten-year cohort. Ann Hepatol 2014;13(04):386-393

52 Fassio E, Díaz S, Santa C, et al; Multicenter Group for Study of Hepatocarcinoma in Latin America; Asociación Latinoamericana para el Estudio del Hígado (ALEH). Etiology of hepatocellular carcinoma in Latin America: a prospective, multicenter, international study. Ann Hepatol 2010;9(01):63-69

53 Appel-da-Silva MC, Miozzo Sda S, Dossin IA, Tovo CV, Branco F, de Mattos AA. Incidence of hepatocellular carcinoma in outpatients with cirrhosis in Brazil: a 10-year retrospective cohort study. World J Gastroenterol 2016;22(46):10219-10225

54 Piñero F, Marciano S, Anders M, et al. Screening for liver cancer during transplant waiting list: a multicenter study from South America. Eur J Gastroenterol Hepatol 2015;27(03):355-360

55 Tzartzeva K, Obi J, Rich NE, et al. Surveillance imaging and alpha fetoprotein for early detection of hepatocellular carcinoma in patients with cirrhosis: a meta-analysis. Gastroenterology 2018; 154(06):1706-1718.e1

56 Bruix J, Sherman M, Llovet JM, et al; EASL Panel of Experts on HCC; European Association for the Study of the Liver. Clinical management of hepatocellular carcinoma. Conclusions of the Barcelona2000 EASL conference. J Hepatol 2001;35(03):421-430

57 Heimbach JK, Kulik LM, Finn RS, et al. AASLD guidelines for the treatment of hepatocellular carcinoma. Hepatology 2018;67(01): 358-380

58 Piñero F, Tisi Baña M, de Ataide EC, et al; Latin American Liver Research, Education and Awareness Network (LALREAN). Liver transplantation for hepatocellular carcinoma: evaluation of the alpha-fetoprotein model in a multicenter cohort from Latin America. Liver Int 2016;36(11):1657-1667

59 Ayuso C, Rimola J, Vilana R, et al. Diagnosis and staging of hepatocellular carcinoma (HCC): current guidelines. Eur J Radiol 2018;101:72-81

60 Méndez-Sánchez N, Ridruejo E, Alves de Mattos A, et al. Latin American Association for the Study of the Liver (LAASL) clinical practice guidelines: management of hepatocellular carcinoma. Ann Hepatol 2014;13(Suppl 1):S4-S40

61 Marrero JA, Fontana RJ, Barrat A, et al. Prognosis of hepatocellular carcinoma: comparison of 7 staging systems in an American cohort. Hepatology 2005;41(04):707-716

62 Forner A, Reig ME, de Lope CR, Bruix J. Current strategy for staging and treatment: the BCLC update and future prospects. Semin Liver Dis 2010;30(01):61-74

$63 \mathrm{Kim}$ KM, Sinn DH, Jung S-H, et al. The recommended treatment algorithms of the BCLC and HKLC staging systems: does following these always improve survival rates for HCC patients? Liver Int 2016;36(10):1490-1497

64 Guarino M, Tortora R, de Stefano G, et al; Progetto Epatocarcinoma Campania Group. Adherence to Barcelona Clinic Liver Cancer guidelines in field practice: results of Progetto Epatocarcinoma Campania. J Gastroenterol Hepatol 2018;33(05):1123-1130

65 Andraus W. Barriers and limitations to access to liver transplantation in Latin America. Clin Liver Dis (Hoboken) 2019;13(02): 36-38

66 Yang JD, Larson JJ, Watt KD, et al. Hepatocellular carcinoma is the most common indication for liver transplantation and placement on the waitlist in the United States. Clin Gastroenterol Hepatol 2017;15(05):767-775.e3

67 Gabrielli M, Vivanco M, Hepp J, et al. Liver transplantation results for hepatocellular carcinoma in Chile. Transplant Proc 2010;42 (01):299-301

68 Hoyos S, Escobar J, Cardona D, et al. Factors associated with recurrence and survival in liver transplant patients with HCC-a single center retrospective study. Ann Hepatol 2015;14(01):58-63

69 Piñero F, Marciano S, Anders M, et al. Identifying patients at higher risk of hepatocellular carcinoma recurrence after liver transplantation in a multicenter cohort study from Argentina. Eur J Gastroenterol Hepatol 2016;28(04):421-427

70 Salvalaggio PR, Felga G, Axelrod DA, Della Guardia B, Almeida MD, Rezende MB. List and liver transplant survival according to waiting time in patients with hepatocellular carcinoma. Am J Transplant 2015;15(03):668-677 
71 Chagas AL, Felga GEG, Diniz MA, et al; Brazilian HCC Study Group. Hepatocellular carcinoma recurrence after liver transplantation in a Brazilian multicenter study: clinical profile and prognostic factors of survival. Eur J Gastroenterol Hepatol 2019;31(09):1148-1156

72 Sapisochin G, Bruix J. Liver transplantation for hepatocellular carcinoma: outcomes and novel surgical approaches. Nat Rev Gastroenterol Hepatol 2017;14(04):203-217

73 Llovet JM, Ricci S, Mazzaferro V, et al; SHARP Investigators Study Group. Sorafenib in advanced hepatocellular carcinoma. N Engl J Med 2008;359(04):378-390

74 Cheng A-L, Kang Y-K, Chen Z, et al. Efficacy and safety of sorafenib in patients in the Asia-Pacific region with advanced hepatocellular carcinoma: a phase III randomised, double-blind, placebocontrolled trial. Lancet Oncol 2009;10(01):25-34

75 Leathers JS, Balderramo D, Prieto J, et al. Sorafenib for treatment of hepatocellular carcinoma: a survival analysis from the South American Liver Research Network. JClin Gastroenterol 2019;53 (06):464-469

76 Piñero F, Marciano S, Fernández N, et al. Intermediate-advanced hepatocellular carcinoma in Argentina: treatment and survival analysis. World J Gastroenterol 2019;25(27):3607-3618
77 DA Fonseca LG, Barroso-Sousa R, Bento AD, et al. Safety and efficacy of sorafenib in patients with Child-Pugh B advanced hepatocellular carcinoma. Mol Clin Oncol 2015;3(04): 793-796

78 Bruix J, Qin S, Merle P, et al; RESORCE Investigators. Regorafenib for patients with hepatocellular carcinoma who progressed on sorafenib treatment (RESORCE): a randomised, double-blind, placebo-controlled, phase 3 trial. Lancet 2017;389(10064): 56-66

79 Abou-Alfa GK, Meyer T, Cheng A-L, et al. Cabozantinib in patients with advanced and progressing hepatocellular carcinoma. $\mathrm{N}$ Engl J Med 2018;379(01):54-63

80 Zhu AX, Kang Y-K, Yen C-J, et al; REACH-2 Study Investigators. Ramucirumab after sorafenib in patients with advanced hepatocellular carcinoma and increased $\alpha$-fetoprotein concentrations (REACH-2): a randomised, double-blind, placebo-controlled, phase 3 trial. Lancet Oncol 2019;20(02):282-296

81 da Fonseca LG, Marta GN, Braghiroli MIFM, et al. Safety and efficacy of cytotoxic chemotherapy in hepatocellular carcinoma after first-line treatment with sorafenib. BMC Cancer 2018;18 (01):1250 